\title{
TEPINGO TESTO IR EKG RODIKLIŲ SĄSAJŲ ANALIZE் VERTINANT SPORTININKUৃ ORGANIZMO FUNKCINES YPATYBES BEI TARPASMENINES SĄVEIKAS
}

\author{
Jonas Poderys ${ }^{1}$, Alfonsas Vainoras ${ }^{2}$, Zenonas Navickas ${ }^{3}$, Liepa Bikulčiené ${ }^{3}$ \\ Lietuvos kūno kultūros akademija ${ }^{1}$, Kauno medicinos universitetas ${ }^{2}$, Kauno technologijos universitetas ${ }^{3}$, \\ Kaunas, Lietuva
}

\begin{abstract}
Jonas Poderys. Biomedicinos mokslų habilituotas daktaras. Lietuvos kūno kultūros akademijos Lengvosios atletikos katedros profesorius, Kineziologijos laboratorijos mokslinis vadovas. Mokslinių tyrimų kryptis — sportuojančiujų parengtumo ir funkcinės būklės kompleksinis vertinimas.
\end{abstract}

\section{SANTRAUKA}

Tarpasmeninè sqveika gali būti tiriama ir vertinama naudojant daugeli metodiku. Dažniausiai yra naudojama asmenu judèjimo detekcija ir aprašymas. Šia metodika gaunama informacija daugiau sietina su galutiniu rezultatu, tam tikro elgsenos modelio formavimu, tačiau mažai arba visai neparodo personaliju vidiniu sasaju.

Tyrimo tikslas - sukurti ir išbandyti laiko eilučiu kointegracinès analizés metoda, kuri naudodami galètume registruoti, aprašyti ir vertinti funkciniu rodikliu kaitos sqsajas ar tarpasmeninès sqveikos ypatybes.

Tiriamieji sveiki sportuojantys asmenys buvo išmokyti, kaip taisyklingai atlikti tepingo testa. Jie pasirinkta ranka daug kartu atliko klasikini 40 s trukmés tepingo testa: 1 - po vienq; 2 - atlikdami kooperacinę užduoti - kiek galima daugiau sinchronišku judesiu su partneriu. Antro tyrimo metu registruota 12-ka standartiniu EKG atvadu tiriamajam esant santykinės ramybès büsenos, pramankštos, maksimalaus ištvermès krūvio metu, per pirmasias tris atsigavimo minutes. EKG buvo registruojama nenutrūkstamai ir diskretizuojama $500 \mathrm{~Hz}$ dažniu. Kaip susijusias tarème esant 2 skirtingas EKG derivacijas, registruotas sinchroniškai. Buvo analizuojama EKG intervalı RR, JT ir QRS komplekso kaitos reikšmès (dQRS).

Šiuo tyrimu pristatoma rodikliu sasajos matematinio vertinimo metodika. Rezultatai parodè, kad laiko eilučiu kointegracinés analizès metodu galima vertinti ̨̇vairiu procesu, tarp jų ir tarpasmenines sasajas ar organizmo funkciniu sistemu sqveikq laiko atžvilgiu, nagrinèti ja skirtingais fraktaliniais lygiais. Jeigu sekos elementai artëja prie nulio, tai rodo, kad pasirinktos duomenu sekos panašeja, mažejja ju individualus informatyvumas, aprašoma vis labiau sqveikaujančiu subjektı sistema.

Raktažodžiai: tarpasmenine squeika, elektrokardiogramos analizé, tepingo testas.

\section{IVADAS}

$\mathrm{N}$ aujų tyrimo metodų, tyrimo duomenu vertinimo būdų kūrimas ir tobulinimas yra nenutrūkstamas procesas. Nauji tyrimo duomenu analizès ir vertinimo metodai leidžia ivvertinti organizmo fiziologinių mechanizmų sinerginès sąveikos ypatybes, kurios negali būti nusakomos iprastiniais euristiniais metodais. Vertinant didelio meistriškumo sportininkų organizmo adaptaciją prie staiga pasikeitusių geografinių ir klimatinių sąlygu buvo pastebėta, kad organizmo funkciniu sistemu tarpusavio sąveikos vertinimas yra jautresnis ir tikslesnis nei vienas atskirai vertinamas nors ir reikšmingas funkcinis rodiklis (Poderys, 2007; Poderys et al., 2008). Kokius vertinimo metodus įvairiu procesų sąveikai vertinti gali pasirinkti tyrejjas? Deja, tokių metodų nėra daug, juolab tinkančių nenutrūkstamai sekti dviejų procesų sąsajų kaitą (Navickas et al., 2005). 
Dviejų ar kelių sportininkų bendradarbiavimas ir jų tarpusavio sąveika yra reikšmingas veiksnys, lemiantis sèkmę ar pralaimejjimą komandinių sporto šakų varžybose. Žinoma, kad vieni sportininkai varžybu aplinkoje geba reikšmingai padidinti savo darbinguma, o kitiems varžymasis yra didžiulè kliūtis, trukdanti realizuoti pratybose sukauptą patyrimą (Malinauskas, 2003). Tarpasmeninèms sąveikoms vertinti nèra sukurta daug metodų, ir šis vertinimas labai aktuali praktikos, mokslo problema. Tarpasmeniné sąveika gali būti tiriama ir vertinama daugeliu metodikų. Viena iš jų — tai žmonių judejjimo detekcija ir aprašymas. Šiomis metodikomis gaunama informacija daugiau sietina su pačiu galiniu rezultatu, tam tikro elgsenos modelio formavimu, visgi mažai arba visai neparodo personaliju vidiniu sąsajų. Šio tyrimo tikslas — sukurti ir išbandyti laiko eilučiu kointegracinès analizès metoda, kuri naudodami galètume registruoti, aprašyti bei vertinti funkcinių rodiklių kaitos sąsajas ar tarpasmeninès sąveikos ypatybes.

\section{METODIKA}

Tiriamaji kontingentą sudarè sveiki sportuojantys asmenys - Lietuvos kūno kultūros akademijos studentai ir Kauno miesto sportininkai (vyrai, $n=12$ ).

Ukrainos mokslininkai A. M. Zelencovas, V. V. Lobanovskis (Зеленцов, Лобановский, 1998) pasiūlè iš esmès naują tepingo testo duomenų vertinimo metodika, skirtą sportininkų CNS funkcinei būklei vertinti. Ši tepingo testo duomenu analizès ir vertinimo metodika taikoma vertinant sportuojančių asmenų funkcinès būklès rodiklius. Pirmo tyrimo metu tiriamieji buvo išmokyti, kaip taisyklingai atlikti tepingo testą. Jie pasirinkta ranka daug kartu atliko klasikini $40 \mathrm{~s}$ trukmès tepingo testą: 1 - po vieną; 2 - atlikdami kooperacinę užduoti - kiek galima daugiau sinchroniškų judesių su partneriu. Kooperacinės užduoties metu tiriamieji kompiuterio ekrane besikeičiančio stulpelinio grafiko forma mate savo ir partnerio atliekamų judesių dažnio santykị ir atitinkamai galëjo derinti tarpusavio veiksmus. Judesių trukmè milisekundėmis buvo registruojama panaudojant kompiuterine programa, sukurta LKKA Kineziologijos laboratorijoje. Kompiuterinė programa užrašinèjo laiko intervalus tarp dviejų atskirų mygtuko spustelejjimu (piršto judesių periodo), ir šis atliktų judesių dažnis buvo panaudotas tiriamojo CNS funkcinei būklei bei tarpasmeninėms sąveikoms vertinti. Funkcinei būklei vertinti buvo apskaičiuojami du klasikinio tepingo testo rodikliai: CNS funkcinis paslankumas - judesių dažnis testo pradžioje ir CNS funkcinis pastovumas — judesių dažnio palaikymas (nemažèjimas).

Antro tyrimo metu registruojama 12-ka standartinių EKG atvadų tiriamajam esant santykinès ramybès būsenos, pramankštos ir maksimalios ištvermès krūvio metu, per pirmąsias tris atsigavimo minutes. Fizinis krūvis buvo atliekamas tiriamiesiems minant veloergometro pedalus 60 aps. / min dažniu: mankšta - $50 \mathrm{~W}$; sunkus fizinis krūvis skiriamas individualiai - $250 \mathrm{~W}$ arba $300 \mathrm{~W}$. EKG buvo registruojama nenutrūkstamai ir diskretizuojama $500 \mathrm{~Hz}$ dažniu. Kaip susijusias tarème esant 2 skirtingas EKG derivacijas, registruotas sinchroniškai. Buvo analizuojama EKG intervalu RR, JT ir QRS komplekso kaitos reikšmès (dQRS).

Pastabose apie matematinių metodų taikymo galimybes pateikiame vieną dvieju skaitmeniniu laiko eilučių tyrimo metodika, kai minètų eilučių elementų reikšmės yra laikomos determinuotomis. Tuo tikslu buvo taikomi antros eilès matricų analizès metodai.

\section{REZULTATAI IR JŲ APTARIMAS}

Matematiniais metodais vertinant tarpparametrinę sąveiką, pirmiausia būtina sudaryti dvi sinchroniškas skaitmenines laiko eilutes $\left(x_{n} ; n=0,1,2, \ldots\right.$ ir $\left.y_{n} ; n=0,1,2, \ldots\right)$, kurios privalo reprezentuoti tiriamaji objektą (čia $x_{n}$ ir $y_{n}$ - realūs skaičiai), pavyzdžiui, tepingo testo arba užregistruotų EKG rodiklių matavimų rezultatus.

Klasikiniai laiko eilučių matematiniai tyrimo metodai yra dvejopi: statistiniai ir analizès. Pirmieji metodai šiuo metu yra gerai išplètoti ir taikomi tada, kai daroma principinè prielaida, kad tiriamųjų laiko eilučių elementai $x_{n}$ ir $y_{n}$ yra atsitiktiniai dydžiai. Antrieji - kada elementai $x_{n}$ ir $y_{n}$ yra laikomi determinuotais. Pastarieji metodai dar tik pradedami plètoti. Jeigu skaitmeninè laiko eilute (arba skaitmeninių laiko eilučių dvejetas) talpina kokią nors informaciją apie tiriamaji objektą, tai ši informacija (jeigu tos eilutès tiriamos matematiniais metodais) būna išreikšta matematinių sąryšiu būdu. Taigi gautuosius sąryšius būtina išmokti interpretuoti, juos adekvačiai siejant su tiriamo objekto ypatumais. Be abejo, tam reikalinga tiek eksperimentinių, tiek matematinių metodų taikymo patirtis. 
I. Tarkime, turime dvi skaitmenines laiko eilutes - kintamu procesu pamatuotu reikšmiu sekas (pavyzdys -1 pav. $\left(x_{n} ; n=0,1,2, \ldots\right.$ ir $\left.\left.y_{n} ; n=0,1,2, \ldots\right)\right)$. Tada iš jų sudaroma matricine laiko eilutè

$$
\left(A_{n} ; n=0,1,2, \ldots\right) . \text { Čia } A_{n}:=\left[\begin{array}{ll}
a_{n} & b_{n} \\
c_{n} & d_{n}
\end{array}\right] .
$$

Koeficientus $a_{n}, b_{n}, c_{n}, d_{n}$ sudarome šitaip:

$$
\begin{aligned}
& a_{n}:=x_{n}, d_{n}:=y_{n}, b_{n}:=\alpha\left(x_{n}-y_{n-1}\right), \\
& c_{n}:=\beta\left(x_{n}-y_{n+1}\right),
\end{aligned}
$$

kai parametrai $\alpha, \beta$ yra parenkami priklausomai nuo laiko eilučių $\left(x_{n} ; n=0,1,2, \ldots\right.$ ir $\left.y_{n} ; n=0,1,2, \ldots\right)$ ypatumų. Taip gaunamos keturios skaitmeninès laiko eilutès $\left(a_{n} ; n=0,1,2, \ldots\right), \ldots\left(d_{n} ; n=0,1,2, \ldots\right)$ ir viena matricu $\left(A_{n} ; n=0,1,2, \ldots\right)$. Savaime suprantama, kad šias eilutes galima sudaryti pasitelkiant ir kitokius matematinius sąryšius.

II. Gautas pirmąsias keturias skaitmenines eilutes galima tirti įvairiais tyrimo metodais. Matricinei laiko eilutei tirti panaudosime šias antros eilès matricu skaitmenines ypatybes ir matricu $A_{n}$ esmines komponentes:

1. $\operatorname{Tr} A_{n}:=a_{n}+d_{n}$ (matricos $A_{n}$ pèdsaku).

2. $\operatorname{dfr} A_{n}:=a_{n}-d_{n}$ (skirtumu).

3. $\operatorname{cdp} A_{n}:=b_{n} \cdot b_{n}$ (kodiagonaline sandauga).

$$
\text { 4. } B_{n}:=\left[\begin{array}{cc}
\frac{\mathrm{dfr} A_{n}}{2} & b_{n} \\
c_{n} & -\frac{\mathrm{dfr} A_{n}}{2}
\end{array}\right] \text { (matricos } A_{n} \text { esmine komponente). }
$$

Iš šių pradinių matricas $A_{n}$ apibūdinančių parametru galime gauti visas kitas taikomają vertę turinčias charakteristikas:

5. $\operatorname{dsk} A_{n}=\left(\operatorname{dfr} A_{n}\right)^{2}+4 c d p A_{n}$ (diskriminanta).

6. det $A_{n}=\frac{1}{4}\left(\left(\operatorname{Tr} A_{n}\right)^{2}-\operatorname{dsk} A_{n}\right)$ (determinanta).

7. $\lambda_{n}=\frac{1}{2}\left(\operatorname{Tr} A_{n}+\sqrt{\operatorname{dsk} A_{n}}\right)$ (matricos $A_{n}$ I tikrinę reikšme) $)$.

8. $\mu_{n}=\frac{1}{2}\left(\operatorname{Tr} A_{n}-\sqrt{\operatorname{dsk} A_{n}}\right)$ (II tikrinę reikšmę) ir pan.

Gautos skaitinės reikšmės parodo įvarius sąryšius. Štai keletas tokių:
III. Matricų analizès teorijoje išskiriamos dvi svarbios matricu rūšys.

I matrica vadinama idempotentu (pastovios galios matrica), jeigu $I^{2}=I$, o $N$ matrica — nulpotentu (matrica, netenkančia galios), jeigu

$$
\mathrm{N}^{2}=0 \text {, kai } 0:=\left[\begin{array}{ll}
0 & 0 \\
0 & 0
\end{array}\right] \text {. }
$$

Pavyzdžiui, esminė komponentė $B_{n}$ yra nulpotentas, jei $\operatorname{dsk} A_{n}=0$, o matricos

$$
I_{n}:=\frac{1}{2} E+\frac{1}{\sqrt{\text { dsk } A_{n}}} B_{n} \text { ir } E-I_{n}-\text { idempotentai, }
$$

jei tik $\operatorname{dsk} A_{n} \neq 0$.

Be to, matricu $A_{n}$ laipsnius $A_{n}^{\alpha}$, kai $\alpha$ - bet koks realus skaičius, galima išreikšti šitaip:

1. $A_{n}^{\alpha}=\lambda_{n}{ }^{\alpha} I_{n}+\mu_{n}^{\alpha}\left(E-I_{n}\right)=\mu_{n}^{\alpha} E+\left(\lambda_{n}{ }^{\alpha}-\mu_{n}{ }^{\alpha}\right) I_{n}$,

$$
\begin{aligned}
& \operatorname{dsk} A_{n} \neq 0, \lambda_{n} \neq \mu_{n} ; \lambda_{n}, \mu_{n} \neq 0 . \\
& \text { 2. } A_{n}^{\alpha}=\mu_{n}^{\alpha}\left(E+\frac{\alpha}{\mu_{n}} B_{n}\right), \operatorname{dsk} A_{n}=0, \lambda_{n}=\mu_{n}, \mu_{n} \neq 0,
\end{aligned}
$$

kai laipsnio rodiklis $\alpha$ ir skaliarinis dydis $\lambda$ - bet kokie realūs skaičiai, o $A_{n} \neq \lambda E$.

Pirmuoju atveju matrica $A_{n}$ vadinama idempotentine, antruoju - nulpotentine. Kai bent viena tikrinè reikšmė yra nulinè, t. y. $\operatorname{det} A_{n}=\lambda_{n} \cdot \mu_{n}=0$, ir skaliarinėms matricoms $A_{n}=\lambda E$ matricos $A_{n}$ laipsnių $A_{n}^{\alpha}$ išraiška nepateikiama.

Tegul egzistuoja ribos dsk $A_{n} \rightarrow 0, b_{n} \rightarrow \bar{b}$, $c_{n} \rightarrow \bar{c}$, tenkinančios sąlygą $\bar{b} \cdot \bar{c} \leq 0$, tada

$$
B_{n} \rightarrow\left[\begin{array}{cc} 
\pm \sqrt{|\bar{b} \cdot \bar{c}|} & \bar{b} \\
\bar{c} & \pm \sqrt{|\bar{b} \cdot \bar{c}|}
\end{array}\right]:=\bar{B}, \overline{\mathrm{B}}^{2}=0
$$

ir dar tinkami tokie ribiniai perejjimai:

$$
\left|\lambda_{n}-\mu_{n}\right| \rightarrow 0, \sqrt{\operatorname{dsk} A_{n}} \cdot I_{n} \rightarrow \bar{B} .
$$

IV. Pateikti antros eilès matricų sąryšiai leidžia gan kokybiškai ištirti matricines laiko eilutes $\left(A_{n} ; n=0,1,2, \ldots\right)$. Pavyzdžiui, tyrimus galima atlikti šitaip. Iš anksčiau pateiktų sąryšių matyti, kad ypatingą reikšmę turi matricu $A_{n}$ diskriminantai, todèl tikslinga sudaryti tokią skaitinę laiko eilutę $\left(\operatorname{dsk} A_{n} ; n=0,1,2, \ldots\right)$ ir ją skyrium ištirti, t. y. pabandyti surasti jos H rangą žinoma, jeigu toks egzistuoja, surasti jos vardiklius ir pan. (Navickas, Bikulčienė, 2005).

$$
\begin{aligned}
& \lambda_{n}+\mu_{n}=\operatorname{Tr} A_{n} ;\left(\lambda_{n}-\mu_{n}\right)^{2}=\operatorname{dsk} A_{n} ; \lambda_{n} \cdot \mu_{n}=\operatorname{det} A_{n} ;\left(\lambda_{n}-\mu_{n}\right)^{2}-\left(\operatorname{dfr} A_{n}\right)^{2}=4 \operatorname{cdp} A_{n} ; \\
& \operatorname{dfr} A_{n}=\operatorname{dfr} B_{n} ; \operatorname{dsk} A_{n}=\operatorname{dsk} B_{n} ; A_{n}=\frac{1}{2}\left(\operatorname{Tr} A_{n}\right) E+B_{n} ; B_{n}^{2}=\frac{\operatorname{dsk} A}{4} E, \text { kai } E:=\left[\begin{array}{ll}
1 & 0 \\
0 & 1
\end{array}\right] .
\end{aligned}
$$



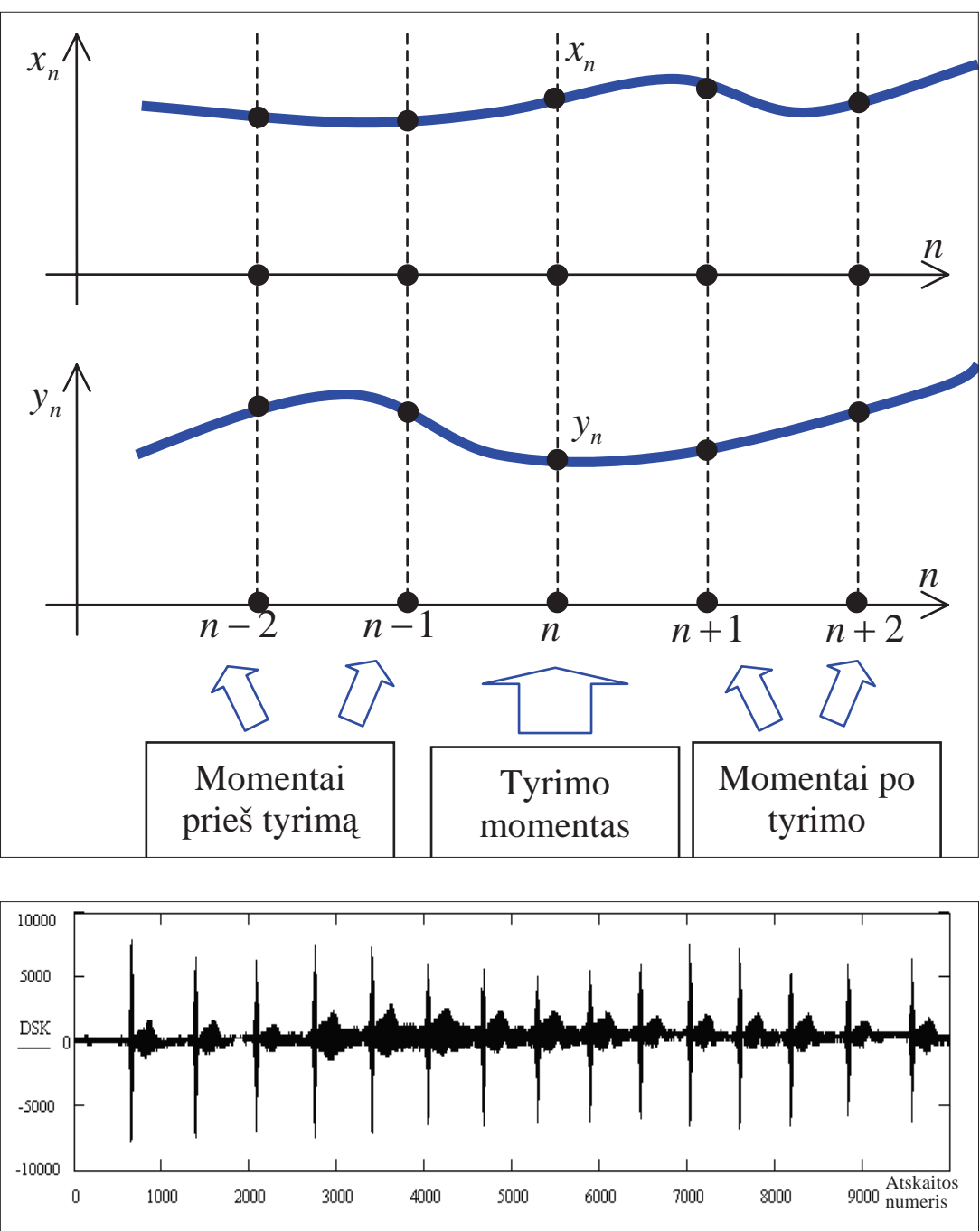

1 pav. Vertinamų procesų pamatuotų reikšmių sekos formavimas kointegracijos procesui vertinti (paaiškinimai tekste)
Čia pravartu žinoti tokią matricų $A_{n}$ diskriminantų invariantinę (pastovumo) savybę. Tegul $T$ bet kokia antros eilès matrica, kurios $\operatorname{det} T \neq 0$. Tada ji turi atvirkštinę matricą $T^{-1}$ ir toks sąryšis yra teisingas: dsk $\left(T A_{n} T^{-1}\right)=\operatorname{dsk} A_{n}$, t. y. i matricą $A_{n}$ panašių matricu $T A_{n} T^{-1}$ diskriminantai yra tokie patys kaip ir matricos $A_{n}$. Be to, dar ir $\operatorname{Tr}\left(T A_{n} T^{-1}\right)=\operatorname{Tr} A_{n}$ ir det $\left(T A_{n} T^{-1}\right)=\operatorname{det} A_{n}$.

Tikslinga pastebèti ir tai: jeigu matricu $A_{n}$ diskriminantai artėja prie nulio, tai matricos $A_{n}$ iš idempotentinių matricų virsta nulpotentinèmis. Vadinasi, duotosios dvi laiko eilutès $\left(x_{n} ; n=0,1,2, \ldots\right.$ ir $\left.y_{n} ; n=0,1,2, \ldots\right)$ panašèja, mažèja jų individualus informatyvumas, ir tai reiškia, kad jos aprašo vis labiau sąveikaujančią interpersonalinę dvieju subjektų sistemą.

Paskui galima sudaryti idempotentinę matricu seką $\sqrt{\operatorname{dsk} A_{n}} \cdot I_{n} ; n=0,1,2, \ldots$ (tuo atveju, kai $\operatorname{dsk} A_{n}=0$, vietoj $I_{n}$ irašome $B_{n}$ ). Iš pastarosios sekos matyti, kaip evoliucionuoja matricinè seka $\left(A_{n} ; n=0,1,2, \ldots\right)$. Pavyzdys pateiktas 2 paveiksle.

Skaičiuojant tikruosius ir pašalinius eilutès duomenis, tikslinga pasirinkti $\operatorname{dsk} A_{n}:=0$, kai tikroji matricos $A$ determinanto reikšmė pasidaro mažesnè už pasirinkto teigiamo dydžio $\varepsilon$ reikšmę.

Sukurto matematinio vertinimo taikymas parodé, kad galima naudoti pati paprasčiausią matricu sudarymo atveji, normuoti ir vidurkinti pradinius duomenis. Normuojant buvo panaudota formulè:

$$
x_{\text {nauja reikšmë }}=\frac{x_{\text {sena reikšmë }}-x_{\min }}{x_{\max }-x_{\min }},
$$

čia $x_{\min }$ ir $x_{\max }$ - minimali ir maksimali nagrinèjamo parametro fiziologinè reikšmè.

Tyrimo rezultatai parodè, kad laiko eilučiuc kointegracinès analizès metodu galima vertinti Łvairių EKG rodiklių sąsajas laiko atžvilgiu. Taip pat tokiam vertinimui pasirinkus rodiklius, parodančius skirtingus organizmo funkcinius lygmenis, - nagrinèti ją skirtingais fraktaliniais lygiais. Jeigu gautos sekos elementai artėja prie nulio, tai rodo, kad pasirinktos duomenų sekos panašeja, t. y. mažèja jų individualus informatyvumas, aprašoma vis labiau sąveikaujančiu subjektų sistema. Kaip parodė šio vertinimo rezultatai, kiekvieno 
3 pav. EKG rodiklių JT ir RR bei RR ir dQRS sąsajos kaita tiriamajam M. K. atliekant ištvermès krūvio testą
4 pav. Dviejų tiriamųjų tarpasmeninės sąveikos įverčio kaita atliekant tepingo testą
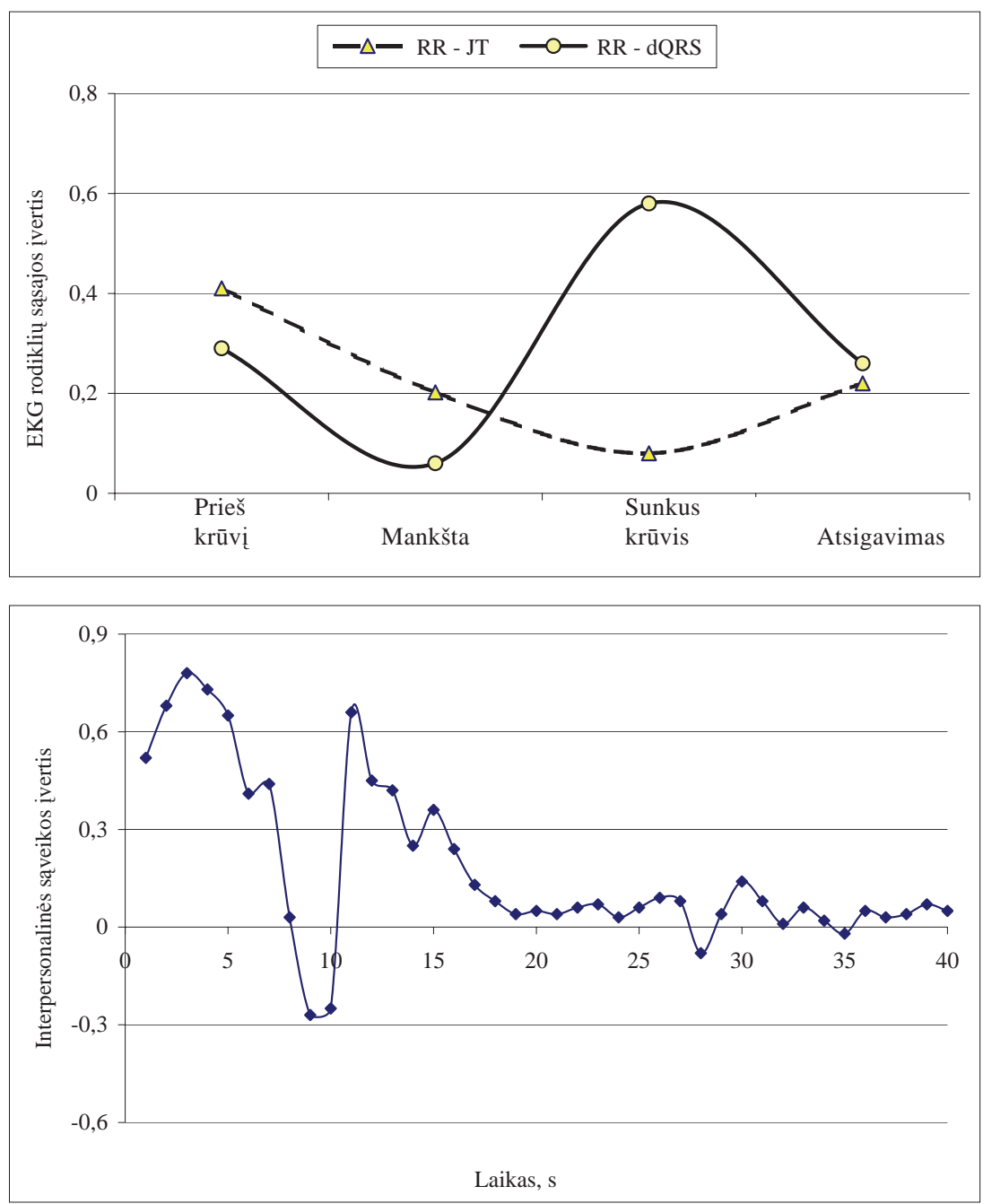

tiriamojo rodiklių sąsajos kaita individuali. Trečiame paveiksle pateikti tiriamojo M. K. EKG rodiklių kaitos ịverčiai, kurių kaitos pobūdis vaizdžiai parodo ir gali paaiškinti fiziologiniu procesu sąsajas. Atskirų EKG rodiklių kaita fizinių krūvių metu parodo reguliacinių, aprūpinančiujų sistemu elgseną (Vainoras, 2002). Taigi tyrimo metu aptiktas sąsajos tarp EKG RR ir JT intervalų didèjimas mankštos ir sunkaus fizinio krūvio metu liudija apie metaboliniu procesu (JT intervalo kaitos) priklausomumą nuo reguliacinių komandų (RR intervalo kaitos).

Tiriamojo M. K. RR ir dQRS reikšmingas sąsajos sumažèjimas rodo iš esmès pasikeitusią tiriamojo būseną sunkaus fizinio krūvio metu (2 pav.). Jeigu lengvo fizinio krūvio metu (mankštos) QRS komplekso kitimai vykdė centrines reguliacines komandas, tai sunkaus krūvio metu šio tiriamojo širdies laidžioji sistema, matyt, nebepajègè sekti ir tiksliai jas vykdyti.

Bandymas vertinti kooperacinės tiriamujų sąveikos ypatybes iš vienu metu registruotu dvieju tiriamuju judesių dažnio kaitos parodè, kad anks- čiau aprašytas duomenų analizès būdas (laiko eilučių kointegracinès analizès metodu) yra tinkamas šiam tikslui pasiekti. Apibendrinant dvieju tiriamujų kooperacinès sąveikos tyrimo rezultatus galima konstatuoti, kad klasikinis tepingo testas leidžia vertinti besikeičiančią tiriamujų funkcinę būklę: dalis tiriamujų tepingo testo metu atlikdavo vis mažiau judesių. Tai rodo CNS funkcinio pastovumo mažèjimą. Kitos dalies tiriamuju rezultatas nemažèjo (vertinant visas suvidurkintas per $40 \mathrm{~s}$ atliktu judesių reikšmes, statistiškai patikimo sumažejjimo nebuvo, $\mathrm{p}<0,05$ ). Tai atitinka kitu autoriu (Shimoyama et al., 1990; Зеленцов, Лобановский, 1998), nustačiusių pakankamai dideli sveiku asmenų CNS funkcinio pastovumo rezerva, duomenis.

Ketvirtame paveiksle parodyta dviejų tiriamuju (L. K ir P. V.) judesių dažnio suderinamumo kaita atliekant $40 \mathrm{~s}$ trukmes tepingo testą. Pateiktas pavyzdys liudija, kad: 1) dominuoja vienas tiriamasis; 2) norint suderinti veiksmus bandymo metu, tiriamiesiems prireikè $18 \mathrm{~s}$. Dviejų tiriamuju veiksmų suderinamumo didèjimą lydi vertinamos 
sekos dsk ${ }_{n}$ elementų artejjimas prie nulio. Taigi tepingo testo duomenu sekos vertinimas matematinių sąryšių būdu esant kooperacinėms situacijoms leidžia atskleisti tiriamuju sąveikos kaitą ir ypatybes.

Svarbi fiziologijos problema yra žmogaus organizmo funkcijų, kaip kompleksinès sistemos, tarpusavio sąsajų kaitos pažinimas (Bruce, 2006). Būtina toliau tirti ir išmokti interpretuoti gautuosius sąryšius, juos adekvačiai siejant su tyrimo užduotimis, tyrimo sąlygomis ir tiriamu objektu ypatumais. Fiziniu pratimu metu veikia visi organizmo sandaros lygmenys: subląstelinis, ląstelių, audiniu, organu̧, sistemų, viso organizmo
(Shepard, 1987; Suarez, Darveau, 2005 ir kt.), todèl labai svarbu pažinti organizme vykstančius pokyčius taikant įvairius fizinius krūvius.

\section{IŠVADA}

Pristatytu laiko eilučių kointegracinès analizès metodu galima vertinti įvairiu procesų, tarp jų ir tarpasmenines sąsajas ar organizmo funkciniu sistemų sąveiką laiko atžvilgiu, nagrinèti ją skirtingais fraktaliniais lygiais. Jeigu sekos elementai artèja prie nulio, tai rodo, kad pasirinktos duomenų sekos panašèja, mažèja jų individualus informatyvumas, aprašoma vis labiau sąveikaujančių subjektų sistema.

\section{LITERATŪRA}

Bruce, W. J. (2006). Where Medicine Went Wrong. Rediscovering the Path to Complexity. Studies of Nonlinear Phenomena in Life Science, 11. London: World Scientific.

Malinauskas, R. (2003). Peculiarities of emotional states of sportsmen in cyclic sports. International Journal of Sport Psychology, 34 (4), 289-298.

Navickas, Z., Bikulčienè, L. (2005). Expressions of solutions of ordinary differential equations by standard functions: Proceedings of the 10th International Conference Mathematical Modelling and Analysis 2005 and 2nd International Conference Computational Methods in Applied Mathematics, June 1-5, 2005, Trakai, Lithuania. Vilnius: Technika. P. 143-150.

Poderys, J. (2007). Adaptation and preparation for the competitions at the Olympic Games in Beijing (Peculiarities of body functioning during exercise after a sudden change of time and environmental conditions). Научнопрактические проблемы спорта высших достижений: материаль международной конферениии, Минск, Республика Беларусь, 29-30 ноября 2007 г. (сc. 3639). Минск: БГУФК.
Poderys, J., Ežerskis, M., Poderytè, K., Vainoras, A. (2008). Body Functioning assessment problems of elite athletes. 2nd International Congress of Complex Systems in Sport (2nd ICCSS). 10th European Workshop of Ecological Psychology (10th EWEP) [elektroninis išteklius]: Book of Abstracts, Madeira, Portugal, 4th-8th November 2008. Madeira: SREC- Direcção de Serviços de Tecnologias Educativas. P. 116-117.

Shepard, R. J. (1987). Exercise Physiology. Toronto Philadelphia: B.C.DECKER INC.

Shimoyama, I., Ninchoji, T., Uemura, K. (1990). The finger-tapping test. A quantitative analysis. Archives of Neurology, 47 (6), 873-888.

Suarez, R. K, Darveau, C. A. (2005). Multi-level regulation and metabolic scaling. Journal of Experimental Biology, 208 (Pt 9), 1627-1634.

Vainoras, A. (2002). Functional model of human organism reaction to load - evaluation of sportsman training effect. Ugdymas. Kūno kultūra. Sportas, 3 (44), 88-93.

Зеленцов, А. М., Лобановский, В. В. (1998). Моделирование тренировки в футболе. Киев. С. 214. 


\title{
ANALYSIS OF FINGER TAPPING TESTS AND ECG SIGNAL IN ASSESSMENT OF PECULIARITIES OF BODY FUNCTIONING AND INTERPERSONAL INTERACTION
}

\author{
Jonas Poderys $^{1}$, Alfonsas Vainoras ${ }^{2}$, Zenonas Navickas ${ }^{3}$, Liepa Bikulčiene ${ }^{3}$ \\ Lithuanian Academy of Physical Education ${ }^{1}$, Kaunas University of Medicine ${ }^{2}$, Kaunas University of \\ Technology ${ }^{3}$, Kaunas, Lithuania
}

\begin{abstract}
The idea of a two-way effect is essential in the concept of interaction between two or more subjects effecting each other. Various methods could be used for the assessment of interpersonal interactions. One of such methods is the analysis of movement behaviour during the tasks. Such analysis provides the information on the task based results and related with the behaviour of participants but it does not show the internal interaction. The aim of the study was to create and test the mathematical method designed for the analysis and the assessment of interpersonal interaction based on co-integration of time sequence data.

During the first investigation the participants of the study, healthy adult males, were instructed and asked to perform the Finger tapping test alone and in pairs, having to synchronize their movements as well as possible.

During the second investigation the subject underwent the endurance stress test. The 12-lead ECG was continuously registered during the warm-up, endurance stress test and recovery.

A special algorithm for the analysis of ECG signal was developed. The results obtained during the analysis confirmed the preposition of the Institute of HeartMath that the ECG signals can disclose some interpersonal interaction. The futures of idempotance or nilpotent were more expressed during the competitive situations than during the tasks requiring the efforts with one accord.

The new assessment methodology based on time series co-integration for interaction between physiological parameters is presented in the paper. The results of the investigation has shown that this analytical method allows evaluating interaction between various processes, for instance, the interpersonal interaction or the interaction of the organism functional systems during a period of time in different fractal levels. If the terms of sequence formed in a special way converge to zero it shows that the chosen time series become similar and describe a more associated system.
\end{abstract}

Keywords: interpersonal interaction, analysis of ECG, Finger tapping test.

Jonas Poderys

Lietuvos kūno kultūros akademija

(Lithuanian Academy of Physical Education)

Sporto g. 6, LT-44221 Kaunas

Lietuva (Lithuania)

Tel +370 37302650

E-mail j.poderys@lkka.lt 